\title{
Molecular cloning of two Pseudomonas flagellin genes and basal body structural genes
}

\author{
Craig Winstanley, ${ }^{1} \dagger$ J. Alun W. Morgan, ${ }^{2} \ddagger$ Roger W. Pickup ${ }^{3}$ \\ and Jon R. Saunders ${ }^{1}$
}

Author for correspondence: Craig Winstanley. Tel: +44203 838408. Fax: +44203838282.

\footnotetext{
1 Department of Genetics and Microbiology, University of Liverpool, Life Sciences Building, PO Box 147, Liverpool L69 3BX, UK

2 Freshwater Biological Association, The Ferry House, Ambleside, Cumbria LA22 OLP, UK

3 Institute of Freshwater Ecology, The Ferry House, Ambleside, Cumbria LA22 OLP, UK
}

\begin{abstract}
Pseudomonas putida strains PaW8 and PRS2000 produce flagellins with apparent molecular masses of $81 \mathrm{kDa}$ and $50 \mathrm{kDa}$ respectively. Two Tn5 insertion mutants of $P$. putida PaW8 lacking the ability to bind the flagellinspecific monoclonal antibody MLV1 were isolated. Mutant PaW8-fig2 contained a Tn5 insertion within a $2.6 \mathrm{~kb}$ EcoRI fragment of the P. putida chromosome carrying putative basal body genes. DNA and deduced protein sequences suggested the presence on this fragment of two complete genes homologous to flgH and flgl from Salmonella typhimurium. The insertion of Tn5 occurred in the $f(g l$ locus and appeared severely to reduce expression of the $P$. putida flagellin gene. A Tn5-containing fragment of DNA from a second mutant, PaW8-flg1, was cloned and found to contain sequences that hybridized strongly with the Pseudomonas aeruginosa flagellin gene. A $2.3 \mathrm{~kb}$ HindIII fragment containing all but 62 bp of the P. putida PaW8 flagellin gene was cloned and used as a probe to identify clones carrying the equivalent gene from $P$. putida PRS2000. Flagellin genes from both $P$. putida strains were sequenced and their amino acid sequences deduced. Both flagellins were found to contain conserved amino- and carboxy-terminal regions when compared to other flagellins, with the central region being more variable. The epitope for MLV1 is likely to lie within this central region of $P$. putida PaW8 flagellin. The deduced molecular mass of $P$. putida PaW8 flagellin (68 kDa) differed significantly from its apparent molecular mass estimated by PAGE, possibly as a consequence of post-translational modification. This was not the case with flagellin from $P$. putida PRS2000, where the predicted and apparent molecular masses were similar.
\end{abstract}

Keywords: Pseudomonas putida, flagellin, population analysis

\section{INTRODUCTION}

Flagella, consisting of a filament, hook and basal body, are organelles responsible for bacterial motility. The production and assembly of bacterial flagella are complex processes that can involve upwards of 40 genes (Macnab,

\footnotetext{
†Present address: Division of Biological Sciences, Coventry University, Priory Street, Coventry CV1 5FB, UK.

$\ddagger$ Present address: Horticulture Research International, Littlehampton, West Sussex BN17 6LP, UK.

The GenBank accession numbers for nucleotide sequence data reported in this paper are L15366 and L15367 for the $P$. putida PaW8 and $P$. putida PRS2000 flagellin genes, respectively, and L15385 for the putative basal body genes.
}

1992). The flagellum of Pseudomonas putida PaW8, a plasmid-free derivative of the TOL-plasmid-containing soil isolate $\mathrm{PaW} 1$, is polar, with the flagellar filament composed of a single flagellin.

Flagella are major antigenic determinants in many bacteria. Antigenic differences amongst bacterial flagellins have been widely reported and for example exploited in the serotyping of Salmonella spp. A number of flagellin genes from different bacterial species have been sequenced including Salmonella spp. (Joys, 1985; Wei \& Joys, 1986), Escherichia coli (Kuwajima et al., 1986), Borrelia burgdorferi (Gassmann et al., 1991), Caulobacter crescentus (Gill \& Agabian, 1983), Roseburia cecicola (Martin \& Savage, 1988), Rbizobium meliloti (Bergman et al., 1991), Bacillus subtilis (Albertini et al., 1991), Campylobacter jejuni (Nuijten et al., 
1990), Serratia marcescens (Harshey et al., 1989) and Pseudomonas aeruginosa (Totten \& Lory, 1990). Comparison of flagellin protein sequences from within and between different bacterial species indicates that these polypeptides are typically conserved at both ends, presumably because such regions are important for the correct assembly of filaments. Five phase-1 flagellin genes from Salmonella were shown to be $99 \%$ identical in nucleotide sequence for the first $300 \mathrm{bp}$ at the $5^{\prime}$ end and the first $200 \mathrm{bp}$ at the $3^{\prime}$ end, whereas the genes show decreasing homology towards the middle portion (Joys, 1985; Wei \& Joys, 1986).

McDonough \& Smith (1976) found variation of molecular mass amongst bacterial flagellins of between 28.6 and $63.2 \mathrm{kDa}$. We have previously reported that $P$. putida PaW8 possesses a flagellin of unusually large apparent molecular mass although the amino acid composition of the $\mathrm{N}$-terminal sequence indicates a strong similarity to other flagellins (Morgan et al., 1991). In this paper we describe the isolation following Tn 5 mutagenesis of mutants of $P$. putida PaW8 no longer able to bind MLV1, a monoclonal antibody that reacts specifically with $P$. putida PaW8 flagellin (Morgan et al., 1991). Sequences flanking the point of insertion of $\operatorname{Tn} 5$ on the bacterial chromosome of such mutants were cloned, enabling the sequencing of the flagellin gene and basal body genes of $P$. putida $\mathrm{PaW}$. The flagellin gene sequence of a second $P$. putida strain, PRS2000, was also obtained. The resulting information was used to evaluate the possibility of using flagellin sequence variation as a strain-specific marker in the analysis of bacterial populations.

\section{METHODS}

Bacterial strains and plasmids. These are described in Table 1.

Construction of Tn5 mutants. Plasmid pLG221, carrying Tn5, was introduced into $P$. putida $\mathrm{PaW} 8$ by conjugation followed by selection on minimal medium containing sodium succinate $(5 \mathrm{mM})$ and kanamycin $\left(100 \mu \mathrm{g} \mathrm{ml}^{-1}\right)$. Resulting colonies were patched on to nitrocellulose filters overlayed on nutrient agar plates containing kanamycin, and incubated at $30^{\circ} \mathrm{C}$ overnight. Colonies were screened for the loss of response to MLV1 as described by Harlow \& Lane (1988). Loss of motility was assessed microscopically and by using soft agar.

DNA manipulations. Whole-cell DNA was prepared as described previously (Winstanley et al., 1993). Bulk plasmid DNA was prepared using Qiagen plasmid midi-kit solutions and columns (Hybaid). For small-scale plasmid isolations the method of Holmes \& Quigley (1981) was used. Restriction endonucleases were obtained from Boehringer. Lambda DNA (Pharmacia) digested with HindIII or HindIII and EcoRI was used as a standard. Agarose gel electrophoresis was carried out by established procedures. Specific DNA fragments were eluted from agarose by the method of Girvitz et al. (1980).

Reaction conditions for ligation with T4 DNA ligase were as recommended by the supplier (Boehringer). Transformation into Eschericbia coli ED8654 or E. coli JM103 was achieved either by the procedure of Cohen et al. (1972), or by electrotransformation using the Gene Pulser apparatus (Bio-Rad) and the method of Dower et al. (1988). For electrotransformation, cuvettes with an electrode gap of $0.2 \mathrm{~cm}$ were used with a field strength of $12.5 \mathrm{kV} \mathrm{cm}^{-1}$. Southern blot techniques and hybridizations were carried out as described previously (Winstanley et al., 1993). DNA fragment probes were labelled with $\left[{ }^{32} \mathrm{P}\right] \mathrm{dCTP}$ (ICN Biomedicals) using a Random Primed DNA Labelling Kit (Boehringer). pUC19 gene banks were screened for flagellin clones by colony hybridization using standard procedures.

Flagellin protein purification and $\mathbf{N}$-terminal sequencing. Flagellin was purified from $P$. putida PaW8 and P. putida PRS2000 as described previously (Morgan et al., 1991). Nterminal sequencing was carried out by $\operatorname{Dr} \mathrm{M}$. Wilkinson, Department of Biochemistry, University of Liverpool, UK.

SDSPAGE, Western blotting and cyanogen bromide digestion. SDS-PAGE was performed on $12 \%$ (w/v) slab gels as described by Laemmli (1970), using the molecular mass marker SDS-6H (Sigma). Western blotting (immunoblotting) was carried out by the method of Towbin et al. (1979). Following transfer, the nitrocellulose filter was submerged in $1 \%(\mathrm{w} / \mathrm{v})$ bovine serum albumin (made in PBS: $0.1 \mathrm{M}$ phosphate buffer containing $0.85 \% \mathrm{NaCl}, \mathrm{pH} 7 \cdot 5$ ) with gentle shaking for $1 \mathrm{~h}$, washed in PBS and left overnight in tissue culture supernatant of cell line MLV1, which produces flagellin-specific monoclonal antibody (Morgan et al., 1991). After three further washes in PBS the filter was placed in a 1:500 dilution (in PBS) of a peroxidase-complexed rabbit IgG to mouse $\operatorname{IgG}$ secondary antibody (Dako) for $1 \mathrm{~h}$ with gentle shaking. After final washes in PBS the filter was placed in a solution containing $20 \mathrm{ml}$ of $3 \mathrm{mg} \mathrm{ml}^{-1}$ 4-chloro-1-naphthol (dissolved in methanol), $80 \mathrm{ml}$ PBS, and $3 \mu$ l hydrogen peroxide $(50 \%, v / v$, solution) until the reaction was completed.

Cyanogen bromide digestion was carried out by the method of Aitken et al. (1989). Digested samples were run on $10 \%$ SDSPAGE gels and Western blotted on to Immobilin P Membrane (Dako) prior to $\mathrm{N}$-terminal sequencing.

DNA sequencing. Double-stranded DNA sequencing of both strands of pUC18 and pUC19-based clones and sub-clones was carried out by the dideoxy-chain-termination method of Sanger et al. (1977) using United States Biochemicals Sequenase kits (Cambridge Bioscience) under the conditions recommended by the supplier, with either universal or synthetic primers. Single stranded DNA binding protein was used routinely to reduce secondary structure.

Computer sequence analysis. Identification of restriction sites, nucleotide sequence alignments, determination of amino acid composition, predicted protein molecular mass, alignments of predicted flagellin protein from P. putida PaW8 or PRS2000 with other flagellins (retrieved from EMBL or GenBank: Pearson \& Lipman, 1988), and construction of sequence similarity dendrograms were carried out using the GCG sequence analysis software package (Genetics Computer Group, University of Wisconsin). Predictions of possible antigenic sites for MLV1 within the $P$. putida PaW8 protein sequence were obtained by using PEPTIDESTRUCTURE from the GCG sequence analysis software package to identify regions of high surface probability and antigenic index, and by using PREDICT (M. Partis, Horticultural Research International, Littlehampton, UK; personal communication), which identifies potential antibody-reactive peptides within a protein sequence by calculating hyrophobic moment, flexibility, antigenicity and $\beta$-turn potential. Most likely candidate regions were taken as those scoring well on both tests. 
Table 1. Bacterial strains and plasmids

\begin{tabular}{|c|c|c|}
\hline Strain/plasmid & Description & Source/reference \\
\hline P. putida $\mathrm{PaW} 8$ & Plasmid-free derivative of TOL-containing soil isolate $\mathrm{PaW} 1$ & Worsey \& Williams (1975) \\
\hline P. putida PaW8-fg1 & $\mathrm{MLV}^{-}$mutant of $\mathrm{PaW} 8$ & This study \\
\hline P. putida $\mathrm{PaW} 8-f g 2$ & $\mathrm{MLV1}^{-}$mutant of PaW8 & This study \\
\hline $\begin{array}{l}\text { P. putida PRS2000 } \\
\text { (ATCC 12633) }\end{array}$ & Widely-studied strain & \\
\hline E. coli ED8654 & Common transformation recipient & Winstanley et al. (1989) \\
\hline E. coli JM103 & Common transformation recipient for $\mathrm{pUC}$ vectors & Yanisch-Perron et al. (1985) \\
\hline E. coli W3110(pLG221) & $\operatorname{Tn} 5$ donor & Boulnois et al. (1985) \\
\hline pBR322 & Cloning vector & Bolivar et al. (1977) \\
\hline pBR325 & Cloning vector & Bolivar (1978) \\
\hline pUC18/19 & Cloning vectors & Boehringer \\
\hline рРТ218 & Cloned $P$. aeruginosa PAK type a flagellin gene & $\begin{array}{l}\text { Totten \& Lory }(1990) \\
\text { gift of Prof. S. Lory }\end{array}$ \\
\hline pLV1020 & Contains $\operatorname{Tn} 5$ & Winstanley et al. (1993) \\
\hline pLV'1026 & $\begin{array}{l}\text { Large Tn5-containing EcoRI fragment of PaW8-fg1 DNA cloned } \\
\text { into pBR322 }\end{array}$ & This study \\
\hline pLV1030/pLV1031 & $\begin{array}{l}2.3 \mathrm{~kb} \text { flagellin-related HindIII fragment of PaW8 DNA cloned into } \\
\text { pUC19 }\end{array}$ & This study \\
\hline pLV1040/pLV1041 & $\begin{array}{l}5 \mathrm{~kb} \text { flagellin-related } K p n \mathrm{I} \text { fragment of PRS2000 DNA cloned into } \\
\text { pUC19 }\end{array}$ & This study \\
\hline pLV1042/pLV1043 & $1.85 \mathrm{~kb}$ SalI fragment sub-cloned from pLV1040 into pUC19 & This study \\
\hline pLV1044 & $\begin{array}{l}\text { Tn5-containing EcoRI fragment of PaW8-fg2 DNA cloned into } \\
\text { pBR322 }\end{array}$ & This study \\
\hline pLV1045 & $\begin{array}{l}2.6 \mathrm{~kb} \text { basal body-related EcoRI fragment of PaW } 8 \text { DNA cloned into } \\
\text { pUC19 }\end{array}$ & This study \\
\hline
\end{tabular}

\section{RESULTS}

\section{Tn5 mutagenesis of $P$. putida PaW8}

Out of approximately 600 colonies screened, three $\mathrm{MLV1}^{-}$mutants were identified. All three were found to be non-motile by microscopic analysis and the inability to

(a)

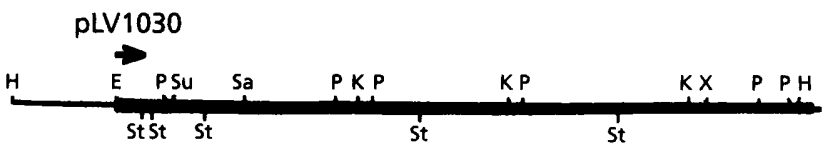

(b)

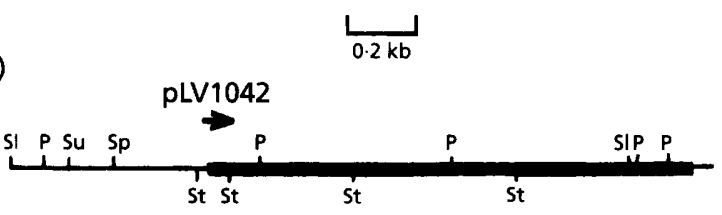

Fig. 1. Restriction enzyme maps of the flagellin gene regions of $P$. putida PaW8 (a) and P. putida PRS2000 (b). Maps were generated using the enzymes EcoRI $(E)$, HindIII $(H), K p n I(K)$, Pstl (P), Sacl (Sa), Sa/l (SI), Sphl (Sp), Stul (Su), Styl (St) and Xhol (X). The position of the flagellin gene is represented in both cases by the thick line. Arrows indicate the direction of transcription which, in pLV1030 and pLV1042, is in the same orientation as vector promoters. spread when patched on to soft agar. Two of the MLV1mutants proved to be identical. Chromosomal DNA from one of these mutants ( $\mathrm{PaW} 8-f g 1$ ) was prepared, digested with EcoRI (no cutting sites within Tn5) and hybridized against a Tn5-specific probe (a $9 \mathrm{~kb}$ EcoRI fragment of plasmid pLV1020: Winstanley et al., 1993). P. putida PaW8-flg1 was found to contain Tn5 within a large (approx. $15 \mathrm{~kb}$ ) EcoRI fragment. This fragment was cloned from $P$. putida PaW8-flg1 DNA into pBR322. The large insert carried by the resulting plasmid, pLV1026, hybridized strongly with a $1.7 \mathrm{~kb}$ HindIII-EcoRI fragment of pPT218 (Totten \& Lory, 1990), carrying $P$. aeruginosa flagellin DNA. Labelled probes made from the cloned inserts of both pPT218 and pLV1026 were used to identify restriction fragments of $P$. putida $\mathrm{PaW} 8$ DNA that contained flagellin-related sequences. These included a HindIII fragment of approximately $2 \cdot 3 \mathrm{~kb}$.

Chromosomal DNA isolated from the third MLV1mutant (named $\mathrm{PaW} 8-f g 2$ ) and digested with EcoRI was also hybridized against the $\operatorname{Tn} 5$ probe and found to contain Tn 5 within an EcoRI fragment of approximately $7 \mathrm{~kb}$.

\section{Cloning of the P. putida PaW8 flagellin gene}

P. putida PaW8 DNA digested with HindIII was cloned into pUC19, and the resulting recombinant plasmids were transformed into E. coli JM103 and screened by colony 


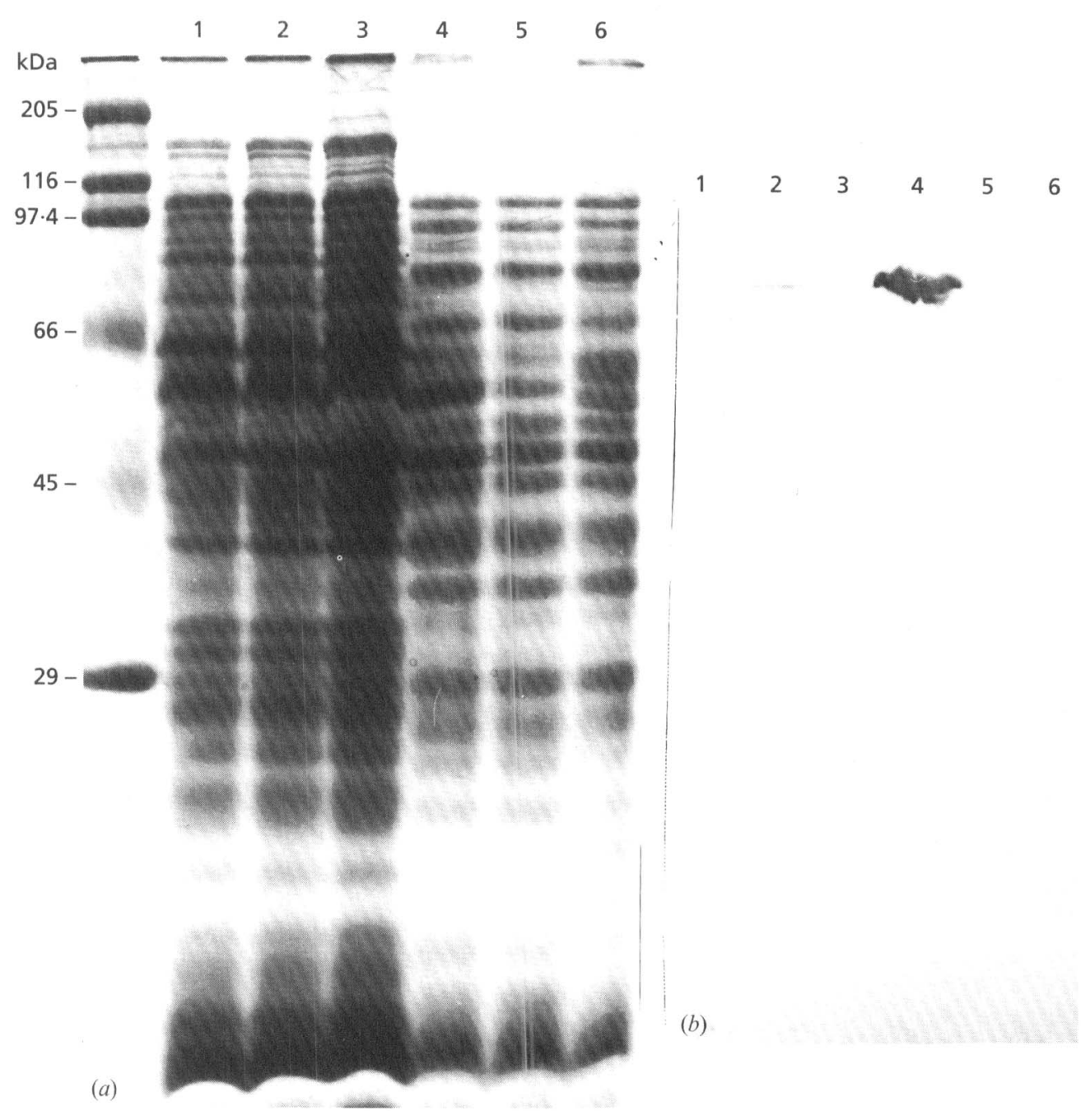

Fig. 2. Western blot of $P$. putida PaW8 flagellin clone against MLV1. PAGE gel (a) and Western blot (b) of: (1) JM103(pUC19); (2) JM103(pLV1030); (3) JM103(pLV1031); (4) PaW8; (5) PaW8-flg1; (6) PaW8-flg2.

hybridization using the large EcoRI cloned fragment of pLV1026 as labelled probe. This resulted in the identification of pLV1030 and pLV1031, which contained a $2 \cdot 3 \mathrm{~kb}$ HindIII cloned fragment in opposite orientations with respect to the pUC19 vector promoter (Fig. 1). Southern blots indicated that both the large EcoRI cloned fragment of pLV1026 and the $1.7 \mathrm{~kb}$ HindIII-EcoRI fragment of pPT218 (containing the $P$. aeruginosa flagellin gene) hybridized with the cloned P. putida PaW $82.3 \mathrm{~kb}$ HindIII fragment of pLV1030 and pLV1031. Fragments of PaW8 DNA that hybridized with the pLV1030/pLV1031 cloned fragment (including a $2.3 \mathrm{~kb}$ HindIII fragment) were of similar size to those hybridizing with the large EcoRI cloned fragment of pLV1026 and the $1.7 \mathrm{~kb}$ HindIII-EcoRI cloned fragment of pPT218 (data not shown). A Western blot of E. coli JM103 containing pLV1030 and pLV1031, using MLV1 antibody, suggested that pLV1030 carries the P. putida PaW8 flagellin gene in the correct orientation for transcription from the pUC19 vector promoter (Fig. 2). No expression was detectable when the HindIII fragment was in the opposite orientation with respect to the pUC19 lac promoter, suggesting that the flagellin gene promoter was recognized poorly or not at all by E. coli RNA polymerase.

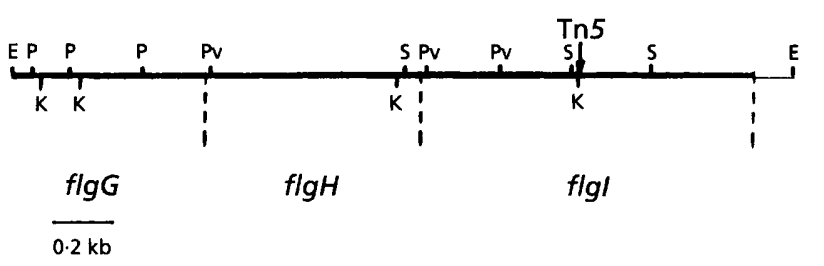

Fig. 3. Restriction enzyme map of the $2.6 \mathrm{~kb}$ cloned EcoRI fragment of pLV1045. The map was generated using the enzymes EcoRI (E), KpnI (K), Pvull (Pv), PstI (P) and Smal (S). The arrow indicates the position of the Tn5 insertion in $P$. putida PaW8-flg2. The boundaries of the $f / g G, f l g H$ and $f / g l g e n e s$ are indicated by vertical broken lines. 
(a) cettcttcgcagcctcaccogetccaccgacgggatgaggcattcagcccagttcaaacagtttttgacgccaataaacc gccettaacccettgatttctcagggctggccccatgccagtattttttttttgaaaaaaccctcaagcaacccgcgcac

ccqacgataaccattacgaaggttctctaggccacaccoggctgtcgccagggccggaagcegcagtatccatacaacga

ggaattcgtcatggctttgaccgttaacaccaacatcacctccatgagtgttcagaagaacctgaacaagtcgtccgacg

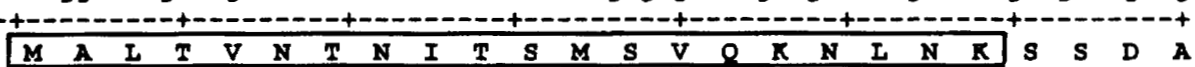

cettgggcaccaccatgggtcgtctgtcctctggcetgaaaa tcaacagtgccaaagacgacgccgcaGGCCTGCACATC ( $\begin{array}{llllllllllllllllllllllllll}I & G & T & T & M & G & R & I & S & S & G & I & K & I & N & S & A & K & D & D & A & A & G & I & Q & I\end{array}$

TCCAAccgtctgaccactcaaatcaaaggtctgagcgttgcggtcaagaacgccaacgatggtatctctattgcgcaaac 481 $\begin{array}{lllllllllllllllllllllllllll}S & N & R & I & T & T & Q & I & K & G & I & S & V & A & V & K & N & A & N & D & G & I & S & I & A & Q & T\end{array}$ tgctgaaggcgccatggcgacttcaggcaaca tcatgcagcgtatgcgtgaactggccetgcaatcggcgaacggctcga

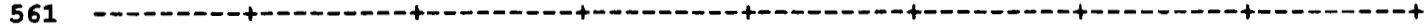

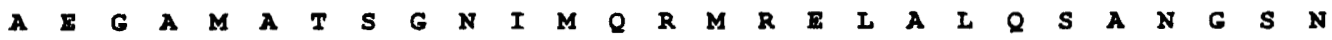
acagcgatgacgaccgcgcctccatgcagcaggagtttaccgcgctgtcgggcgagctcacecgtattgctaacaccacc

641 $\begin{array}{llllllllllllllllllllllllll}S & D & D & D & R & A & S & M & Q & Q & E & F & T & A & L & S & G & E & I & T & R & I & A & N & T & T\end{array}$

actttcggtggccgtaatctgctcgatggcaccttctcoggcagcagcttccaggttggcgcgaactccaacgaaagcat

721 -

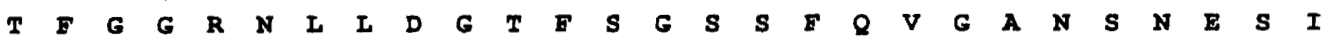

ttcgtttggcatgaaagatgtcagcgctacctcgatgaagggcaactacaacgaagccagcgttgccggcggtgttgcta 801 $\begin{array}{llllllllllllllllllllllllllll}S & F & G & M & K & D & V & S & A & T & S & M & K & G & N & Y & N & \mathbf{E} & A & S & V & A & G & G & V & A & T\end{array}$ ccctgcaagccagcgtcaccggtgcagccggtaagttcggcaccaacaatgctggcagcacttctgcttcggttgtgggt 881 -

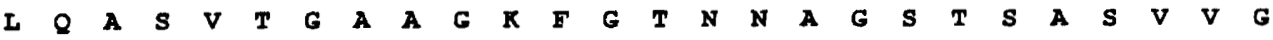
actgcaggcgcgggcgtatttgataagccgaccatcggtgctgctgcoggtaacttggtgctgaacgttggtaccaccac 961 -

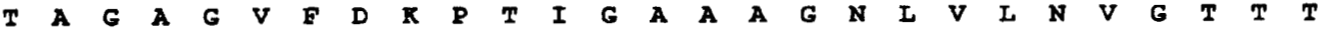
caccaccatcgctgctgcggcaggcgacaccctgcaggatgtggttgacaatatcaacctggaaactagcaataccggtg 1041

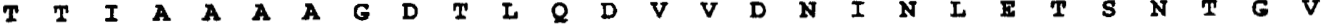
ttaccgctagcattgacagcgccactggtgcactgaagctcgacggcacccaggcattcaccatcgatgccagcactgat 1121

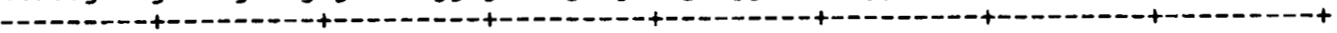

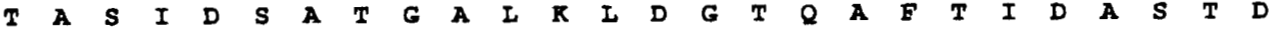

gacgtcttgagcactgcettgggtctggcegaggceggtggtgcceagctgtcgaaaaccggtactgccaacctgcgtga 1201 D

tggtgtattgggggccggtggtgccggtaacctgacgctoggctctaccaacattgcattggttgcgactgacaccetat 1281 $\begin{array}{lllllllllllllllllllllllllll}G & V & \text { I } & G & \text { A } & G & G & A & G & \text { N } & \text { I } & \text { T } & \text { I } & \text { G } & \text { S } & \text { T } & \text { N } & \text { I } & \text { A } & \text { I } & \text { V } & \text { A } & \text { T } & \text { D } & \text { T } & \text { L } & S\end{array}$ cttcggtagtcggcaaggttaatgctcaaaccggcacgactggtgtaacggcttccattgacagtgccactgggcaactg 1361 $\begin{array}{lllllllllllllllllllllllllllllllllll}S & V & V & G & K & V & N & A & Q & T & G & T & T & G & V & T & A & S & I & D & S & A & T & G & Q & L\end{array}$

aactgaactcggctgccggcttcgacgtaggtggtactgcgggtaccttgactggcctgggtctgactgcaggttctgt

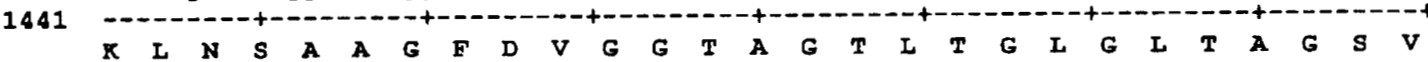

Fig. 4. For legend see p. 2025. 
tgccatcgcgcctcagactaccggtctggcgtcggctgcttcgatcgacatcaatggcactaccttcaacttcgctcaag 1521

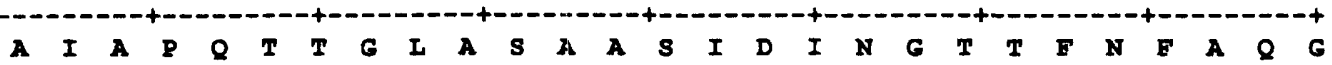

gggatgacctggatgcgatcgttgacaacatcaacaacaacggtgcaggtgctgtoggttcgggtactgccetgactggc

1601

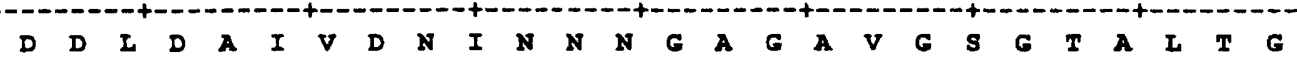

gtcactgccaaaaatgataacggtcgcctggtgctgacttcggccaatggccaggacatcaagttggacaatggttctgg 1681 -

cgtgactgggcaaggggcactggctgccgtaggtctgaactcgggcaccaccaaggetggtttggttgctgatacctcca 1761 cgtgactgggcaaggggcactggctgcegtaggtetgaactcgggcaccaccaaggotggtteggttgetgatacotcoa $\begin{array}{llllllllllllllllllllllllllllll}V & T & G & Q & G & A & I & A & A & V & G & I & N & S & G & T & T & K & A & G & I & V & A & D & T & S & I\end{array}$

tctctctgaacggcgtagaagtcaagttcaagaaaggtgatgacatggatagcatcgcagcctccatcaacgcogccagc 1841 tetctctgaact-$\begin{array}{llllllllllllllllllllllllllll} & S & I & N & G & V & E & V & K & F & K & K & G & D & D & M & D & S & I & A & A & S & I & N & A & A & S\end{array}$

accggtgtcaacgccagcgttgtggttaatgccggcagcagcactctgtcgctgttcgctgaccaggacatcaccgttgc 1921 T G V N A S V V V N A G S S T I S I $S$ A D 0 D I T $V A$

tgatggcagcaatggtaccggtctggcacgacgagctgggtctgactgctgttgcaggcagacctctgcactcgagatgg 2001 D G S N G T G I A R R A G S D C C C R O T S A I $I$ G

aatctaccgtttccaacctgaacatcacggacgcgcaaagtgctcagcaggctatccaggttctggatggtgccatgcag 2081

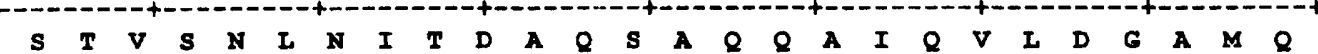

tcgctggactcccagcgttcccagctgggtgcagtgcagaacogtttcgatagcactgtcgctaacctgcagtcgatctc 2161 $\begin{array}{lllllllllllllllllllllllllll}S & I & D & S & Q & R & S & Q & L & G & A & V & Q & N & R & F & D & S & T & V & A & N & I & Q & S & I & S\end{array}$

ggaaaactccaccgeagccogtagtcgtatccaggatgccgactttgctgccgaaactgcggagctgagcaagcagcaaa

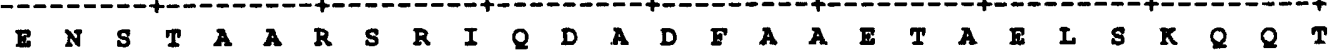

cectgcagcaagcttccaccgctatcetgtcgCAGGCGAACCACCrGCCatcttcggtactgaagctgctcggctaattc (

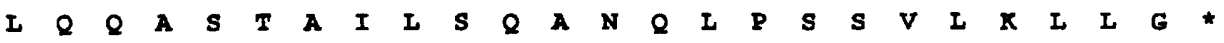

gattctgtgatgaatcgcgaaagggtgcggcaacgtaccetttcgttttctgattctacgaggcaagcatcatggatatg agtgtcaagctgaactctgttctctctgcgccogccactcaagaagccagg

a

2531

(b) tttggagtggtttttgacgccaataaaccgccttaacccettgatttatcggggctggcccoatgccagcatttttttt cgaaaaacccetcaagcatcccqcqcaccegacgataactattacgaaggttctctaggccagtccggcggttgccaagg coggaagccgcagtacccatccaacgagqatttogtcatggctttaactgtaaacaccaacattgcgtcgatcactactc

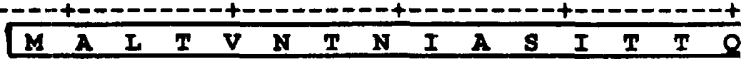

agggcaacctgaccaaggctagcaacgctcagaccacttcgatgcagcgtctgtcctcgggtctgcgtatcaacagegct

aaagacgacgetgCCGGCCTCCACATCGCCAACCgtctgaccagccagatcaatggcetgggccaggctgtcaagaacgC

Fig. 4. For legend see facing page. 
tggccetgtgctcggctactggctcgctgagcaacgcagaccgtaagtcgaacaacgacgaataccaggctctgaccgct

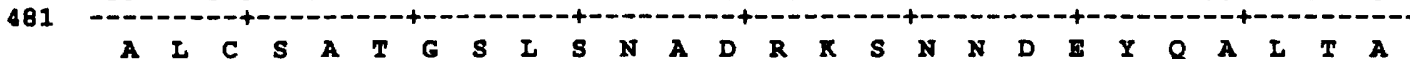

gagctgaaccgtatctgccaaaccaccaccttcggtgccagaagctgctggacggttcgtacggcaccaaggccatccag

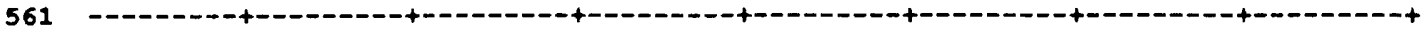

$\begin{array}{lllllllllllllllllllllllllll} & I & N & R & I & C & Q & T & T & T & F & G & A & R & S & C & W & T & V & R & T & A & P & R & P & S & R\end{array}$

gtcggcgccaacgccaacgaaaccatcaacctggcgctggacaacgtttcggccaagagcatcggctcgcagcagatcaa

641 -...-

$\begin{array}{llllllllllllllllllllllllllll} & S & A & P & T & P & T & K & P & S & T & W & R & W & T & T & F & R & P & R & A & S & A & R & S & R & S & S\end{array}$

gtcgggcactatcgcgcctagcceagcgtgtggccgcagctgatctggttgtcactggcaacggtcagagcaaaaccgtc

721

$\begin{array}{llllllllllllllllllllllllll}R & A & I & S & R & I & A & Q & R & V & A & A & A & D & I & V & V & T & G & N & G & Q & S & K & T & V\end{array}$

800

agctatgatgcgggctcctcggccaaagacatcgctgccaaactcaatggctccatcggtggcetgactgcttctgccag

801 -

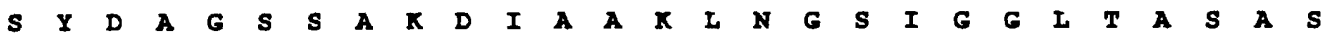

880

caccgaagtcaaactggctgttgccagtggcgctgcagctactccagccaactttgacctgactgtaggcggtacgaccg

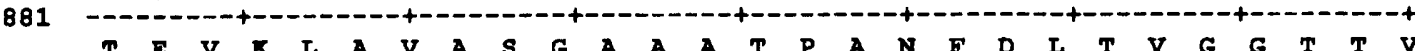

960

tcagcttcatcggtgttactgacaccgcaagcetggctgatcagctgaagtccaacgccgccaagctgggtatcagcgtt

961 (

aactacgacgaatcgaccaagagcctgtcggtgaagtcggacactggcgagaacctggccttcacctccaaggccggcgc

1041

-

1120

agacgccatctcggtgggtgcacgcgacggcaacggtgatttcccaggtactctgaccacgctttcegctaccgttaacg

1121 -

acaaatcgaccgttactggccagatttctctggactctgccaaaggttactcggtagctaacggcgccaccggtactggc

1201

$\begin{array}{llllllllllllllllllllllllll}K & S & T & V & T & G & Q & I & S & L & D & S & A & K & G & Y & S & V & A & N & G & A & T & G & T & G\end{array}$

1280

gctaccgacctgttcggtgcagcttccaagtcctcggccaagaccaccatcgcegataccgatgttaccgaggccgtcaa

1281

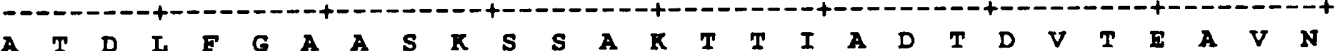

1360

cgcccagaacgccetggccgttatcgacaaggccatcggttcgatcgacagcgtcogttcgggcetgggtgctacccaga

1361 -

$\begin{array}{lllllllllllllllllllllllllll}A & 2 & N & A & L & A & V & I & D & K & A & I & G & S & I & D & S & V & R & S & G & I & G & A & T & Q & N\end{array}$

1440

accgtctgcaaaccaccgtcgacaacctgcagaacatccagaagaactccaccgctgcccgctccaccgtgcaggacgtg

1441

$\begin{array}{llllllllllllllllllllllll}R & L & Q & T & T & V & D & N & L & Q & N & I & Q & K & N & S & T & A & A & R & T & V & Q & V\end{array}$

1520

gacttcgcttcggaaactgccgagctgaccaagcagcagactctgcagcaggcttcgactgcgatcctgttgCAGGCTAA

1521

gactectetecto

1600

CCAGCTGCCatcttcggtcctgaaactgctccagtaattcaggcgcctgagtaaagggtgaaaggg

1601 -

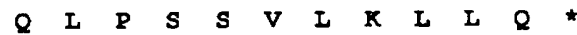

Fig. 4. Nucleotide sequences of the flagellin genes of $P$. putida PaW8 (a) and P. putida PRS2000 (b). Nucleotide and deduced amino acid sequences for the flagellin genes and potential operator-promoter regions are shown. Known $\mathrm{N}$ terminal sequences of both flagellins and peptide P1 are boxed. Possible RpoF-like recognition sequences are underlined. $\mathrm{N}$-terminal sequences of $\mathrm{P} 1$ and PRS2000 flagellin (from purified flagellin) were obtained in this study. The $\mathrm{N}$-terminal sequence of PaW8 flagellin has been reported previously (Morgan et al., 1991). Potential ribosome-binding sites are indicated by double underlining. Sequences corresponding to oligonucleotide primers that can be used for PCR of Pseudomonas flagellin gene sequences are capitalized.

Sequence analysis proved subsequently that the $2.3 \mathrm{~kb}$ HindIII fragment of pLV1030 does not contain $62 \mathrm{bp}$ at the carboxy-terminal end of the flagellin coding sequence.
Thus E. coli JM103(pLV1030) produces a flagellin that is not quite complete. However, cloned flagellin, despite lacking some 20 amino acid residues at the carboxy- 


Paw8
PAK
PRS2000
Paw8
PAK
PRS2000
Paw8
PAK
PRS2000
PawB
PAK
PRS2000
Paw8
PAK
PRS2000

1050

50

100

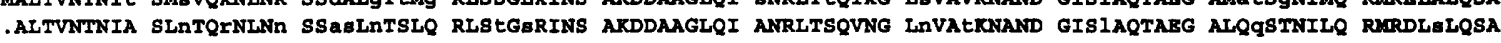
MALTVNTNIA SItTQgNLtK aSNAqTTSMQ RLSSGLRINS AKDDAAGLI ANRLTSQING LgqAVKAAND GISIAQTAEG AMQASTAILQ KMREIALCSA

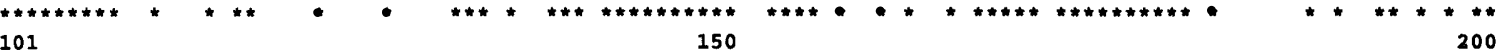
NGSNSDADRa SMqqBFtALA gRLtRIaNTT TFGGRnLLDG tFBgSSFQVG ansNESISfG mkDVSATSMk GnYneAsvAG gVatlqASvT gaagkfgtnn NGSNSDBERt aLNgEakgLq kELdRIBNTT TFGGRkLLDG BFgVaSFQVG GAaNBiISvG idRmSAeSLn GTYfkAdgge avtaatASgT vd1a. .... tGSISnaDRk SnNdEYqALt aBLnRICqTT TFGaR.......... ScWtVr tAprpsrsap tptkpsTwrw tTruprasAr erseralsrl aq........

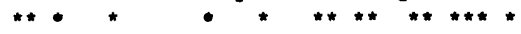

201

250

300

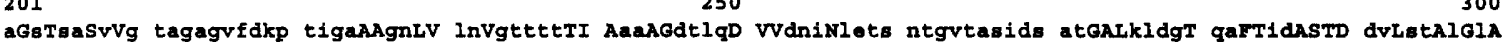
iGiTggsavn ................ vkvdmkgnet AeqAaakiaa avndaNv... ....... giGAFsdGdT isYvakAgkD ........ $\ldots \ldots \ldots \ldots \ldots \ldots \ldots$ rvaAadiv vtgngqskTv sydAGssakd IaaklN................. Gsi ggLTasAstz vkLavAsGaA

$301 \quad 350$

eaggaqlakt gtanlidgul gagGaGnLTl GaTnIaLVat dtlssvvGkV nAqTGtTGVt asidsargqL klnsaagfd gGTAgtltgl gltagSvAIA

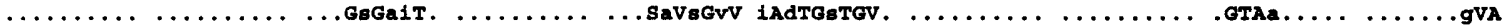
.............. atpanfdLTv GgTtVsFIgv tdtasladql ksnaaklGIs vnyDesTksL svksdtGenl aft..........SkAgA $401 \quad * \quad 450 \quad$ * 400

PqtTgIAsaa aiDingTtfn Faggddldai vdninnngag avgsgtaltg vtakndngri vltsangqdi kldngSgvTG egalaavgln sgttkaglva

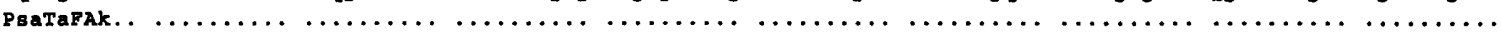

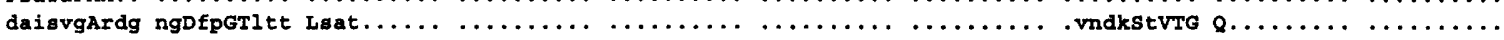

$501 \quad 550 \quad 600$

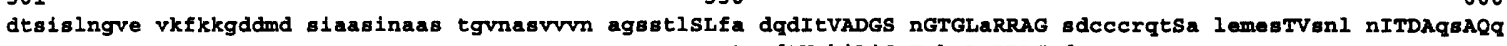

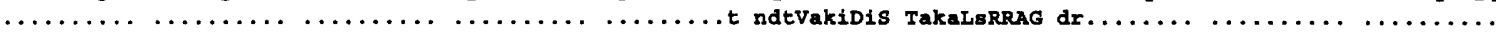

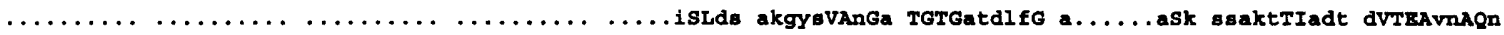

$601 \quad 650 \quad 689$

AiqVIDgAmq SIDSqRSqLG AVQNRFDETV ANLQBIBENS TAARSRIQDa DFAAETARLB KQQTLQQAST AIL\&QANQLP SSVLKLLG

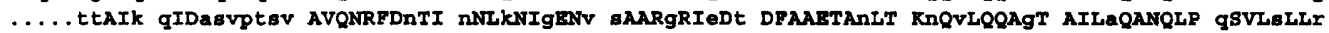
AlaViDkAIg SIDSVRSgLG AtQNRLgtTV dNLQNIqkNS TAARStVQDV DFABKTARLT KQQTLQQAST AILIQANQLP SSVLRLLG

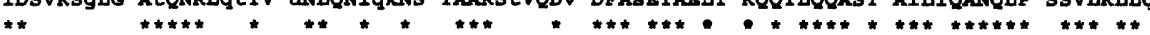

Fig. 5. Alignment of Pseudomonas flagellins. The best-computer-assisted alignment of $P$. putida PaW8, $P$. aeruginosa PAK and $P$. putida PRS2000 flagellins is shown. Capital letters indicate consensus amino acid residues. Asterisks indicate residues common to all three proteins.

terminus, migrated on SDS-PAGE gels with a similar molecular mass to flagellin isolated from P. putida PaW'8 $(81 \mathrm{kDa})$.

\section{Cloning of the P. putida PRS2000 flagellin gene}

Using the $2.3 \mathrm{~kb}$ HindIII fragment of pLV1030 as probe, restriction fragments of $P$. putida PRS2000 chromosomal DNA containing flagellin-related sequences were identified, including a SalI fragment $(1.85 \mathrm{~kb})$ and a $K p n \mathrm{I}$ fragment (approximately $5 \mathrm{~kb}$ ). Using colony hybridization for screening, the $K p n \mathrm{I}$ fragment was cloned onto pUC19 in both possible orientations to create pLV1040 and pLV1041. The $1.85 \mathrm{~kb}$ Sall fragment was sub-cloned from pLV1040 into pUC19 in both possible orientations to create pLV1042 and pLV1043 (Fig. 1). Southern blots of pLV1040 and pLV1041 DNA hybridized strongly against labelled probes of the $2.3 \mathrm{~kb}$ HindIII fragment of pLV1030 (containing almost all of the P. putida PaW8 flagellin gene) and the $1.7 \mathrm{~kb}$ HindIII-EcoRI fragment of pPT218 (containing the $P$. aeruginosa flagellin gene).

\section{Cloning of a $2.6 \mathrm{~kb}$ EcoRl fragment containing flagellar-related DNA}

The $7 \mathrm{~kb}$ Tn5-containing EcoRI fragment of chromosomal DNA from P. putida PaW8-fg2 was cloned into the EcoRI site of pBR322. When labelled, the $7 \mathrm{~kb}$ insert present in the resulting recombinant pLV1044 hybridized with a $2 \cdot 6 \mathrm{~kb}$ EcoRI fragment of $P$. putida PaW8 DNA. $P$. putida PaW8 DNA was digested with EcoRI and subjected to agarose gel electrophoresis. Fragments within the relevant size range were eluted and cloned into EcoRIdigested pBR325. Potential clones were screened subsequently by colony hybridization using the $7 \mathrm{~kb}$ insert of pLV1044 as a probe to identify flagellar gene sequences. pLV1045, containing a $2.6 \mathrm{~kb}$ EcoRI insert in pBR325, was thus identified. Fig. 3 shows a restriction map of pLV1045. The origin of the $2.6 \mathrm{~kb}$ insert DNA was confirmed by Southern blot analysis of digests of $P$. putida PaW8 DNA using the $2.6 \mathrm{~kb}$ fragment as a radioactively labelled probe (data not shown).

\section{Flagellin gene and deduced protein sequences}

The entire $2.3 \mathrm{~kb}$ HindIII cloned fragment of pLV1030 and pLV1031 was sequenced using a number of internal PstI sub-clones for confirmation. The remaining $62 \mathrm{bp}$ of the flagellin gene coding sequence was obtained by extending downstream of the $2.3 \mathrm{~kb}$ HindIII fragment using appropriate synthetic oligonucleotide primers and pLV1026 DNA as template (Fig. 4a). The P. putida PRS2000 flagellin gene was also sequenced using a number of internal Pst I sub-clones for confirmation (Fig. $4 \mathrm{~b})$. When compared with previously reported flagellin gene sequences, the $P$. putida genes exhibited greatest homology with that from $P$. aeruginosa (Fig. 5). The only possible reading frames for flagellin genes are indicated 


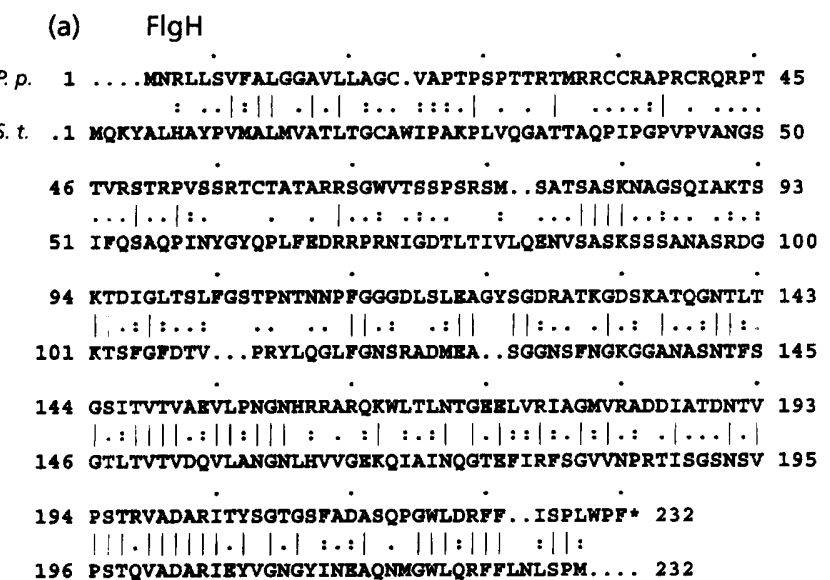

(b) $\mathrm{Flgl}$

P. p. 1 MTNVRQLIATTILLSCAFAAQAERLKDIASISGVRSNQLIGYGLVVGLNG 50 $: .:|\ldots:| .|\quad|:|||::|: .|:||| \cdot||||||||||: \mid$

s. t. 1 ..MTXALAGIVLALVATLAHARRIRDLTSVQGVRENSLIGYGLVVGLD 47

51 TEDQTTQTPFTLQT FNAMCSQGGIKVPAGSGNVQLRNVAAVSVHADLPPF 100 ||||||||||||$:||||||:|| \cdot|| \cdot|\cdot|:||||||||||||||$. 48 TODQTTQTPFTTQTLNNAL SQLGITVPTG. TNMQLKNVAAVMVTASYPPF 96

101 AKPGOVVDITVSSIGNSKSLRGGSLLMTPLKGIDGNVYAIAQGNLVVGGF 150 $|:|.|.:|: .|||:||\cdot||||||\cdot||||||||:|: .|||:||||::|||$ 97 ARQGQTIDVVVSSMGNAXSLRGGTLIMTPLXGVDSQVYALAQGNILVGGA 146

151 DAPGRDGSKITVIVPSAGRIPGGASVERAVPSGTNQGNTLTLNLNRPDFT 200 $:|::||.:||\quad .:||| . .||:|| .:|\ldots| . .|||:.| .|| \cdot|| \mid$ 147 GASA. GGSSVQVNQINGGRITNGAIIERELPTQFGAGNTINLQLNDEDTT 195

201 TAKRIVDKVNDLLGPGVAQAVHGGSVRVSAPMDPSQRVDYLSILENLEID 250

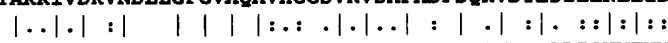
196 MAQQITDAINRARGYGSATALDARTVQVRVPSGNSSQVRFLADIQNMEVN 245

251 PGOAVAKVIINSRTGTIVIGQNVKV. SPAVTHGSLTVTITEDPIVSOP.G 298

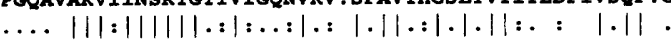
246 VTPQDAKVVINSRTGSVVMVREVTLDSCAVAQGNLSVTVNRQLNVNOPNT 295

299 AFSNGQTAVVPRSRVNAEQEAKPMFKFGPGTTLDEIVRAVNQVGAAPGNL 348 $:|:|||. .|.| \ldots::|.: .: \ldots . . .|:. \ldots|||:| .:|| \cdot|:|$

296 PFGGOOTVVTPOTOIDLROSGGSLOSVRSSANLNSVVRALNALGATPMDL 345

349 MAILEALKHRP. LQADLIVI* 368

|.|1:.:. . | |.|.|:

346 MSILOSMOSAGCLRAKLEII. 365

Fig. 6. Alignment of $P$. putida and $S$. typhimurium $\mathrm{FlgH}$ and Flgl. The best computer-assisted alignments of $P$. putida (P.p., upper sequence) and S. typhimurium (S.t., lower sequence) FlgH (a) and Flgl (b) polypeptide sequences are shown. Identical residues are indicated by a vertical line. Two dots represent a greater similarity than one dot.

and translational start sites were located by comparison with $\mathrm{N}$-terminal amino acid sequences already known (Fig. 4).

Cyanogen bromide treatment of $P$. putida PaW8 flagellin yielded a peptide (P1) of $45-50 \mathrm{kDa}$ that reacted with the strain-specific monoclonal antibody MLV1. The Nterminal sequence of P1 was obtained (MKGNYNEASVAGGVA) and used to locate the peptide within the deduced sequence of PaW8 flagellin (residues 169-519) (Fig. 4). These data confirm the assignment of the flagellin open reading frame (ORF).

\section{DNA sequencing of the $2.6 \mathrm{~kb}$ EcoRI cloned fragment} of $P$. putida PaW8-flg2

The $2.6 \mathrm{~kb}$ EcoRI fragment was sequenced (GenBank accession number L15385) and potential ribosome-binding sites (GAGG for $f g H$ and GGA for $f g I$ ) were identified. Computer-assisted DNA alignments suggested that most of a gene homologous to Salmonella typhimurium flgG (encoding a rod protein, FlgG : Homma et al., 1990) was present within the $2.6 \mathrm{~kb}$ cloned fragment $(60 \cdot 2 \%$ identity in $674 \mathrm{bp}$ overlap of DNA upstream from the $\mathrm{fgH}$ transcriptional start site; sequence alignments suggest that approximately 120 bases at the N-terminal end of $\operatorname{fg} G$ are not present on the fragment). Alignments also identified two complete ORFs downstream of the putative $f g G$ gene aligning well to the $S$. typhimurium $f g H$ (encoding L-ring protein, $\mathrm{FlgH}$ ) and $f g I$ (encoding P-ring protein, FlgI) gene respectively (Jones et al., 1989). Sequencing of pLV1044 DNA showed that $\operatorname{Tn} 5$ in the mutant $P$. putida $\mathrm{PaW} 8$ - flg2 was located within the putative fgI gene (Fig. 3).

\section{Deduced protein sequences of flagellar basal body genes}

The deduced protein product sequences of the putative $\mathrm{fgH}$ and $f g I$ genes were obtained and analysed. Comparisons with previously reported protein sequences confirmed that the best alignments (Fig. 6) were against the flagellar L-ring protein precursor ( $\mathrm{FlgH})$ and flagellar P-ring precursor (FlgI) of S. typhimurium. Translational start sites were deduced by comparison with the corresponding $S$. typhimurium genes and by the location of possible ribosome-binding sites.

\section{DISCUSSION}

\section{Flagellin genes and proteins}

Analysis of the DNA sequence of pUC19, downstream of the HindIII cloning site, suggested that pLV1030 may produce a fusion protein consisting mostly of flagellin with 27 vector-sequence-derived amino acid residues at the $\mathrm{C}$-terminus. The difference in size between this fusion protein and the native flagellin was not detectable by SDS-PAGE. The size of $P$. putida PaW 8 flagellin $(81 \mathrm{kDa})$ is larger than the predicted molecular mass $(68.2 \mathrm{kDa})$ derived from the deduced protein sequence. Flagellins are known to migrate aberrantly in SDS-PAGE (Simon et al., 1977). Post-translational modification may account for changes in molecular mass, as has been observed in flagellins from a number of bacterial species (Joys \& Kim, 1978; Logan et al., 1989; Wieland et al., 1985). KellyWintenberg et al. (1990) have reported the presence of phosphorylated tyrosines in the flagellin of $P$. aeruginosa PAO. The deduced molecular mass of the $P$. putida PRS2000 flagellin $(49 \cdot 2 \mathrm{kDa})$ was similar to the apparent molecular mass estimated by PAGE $(50 \mathrm{kDa})$, suggesting that post-translational modification does not play a significant role in the flagellin of this strain. Computerassisted analysis of deduced protein sequences confirmed that the $P$. putida flagellin genes showed strong homology 
(a)

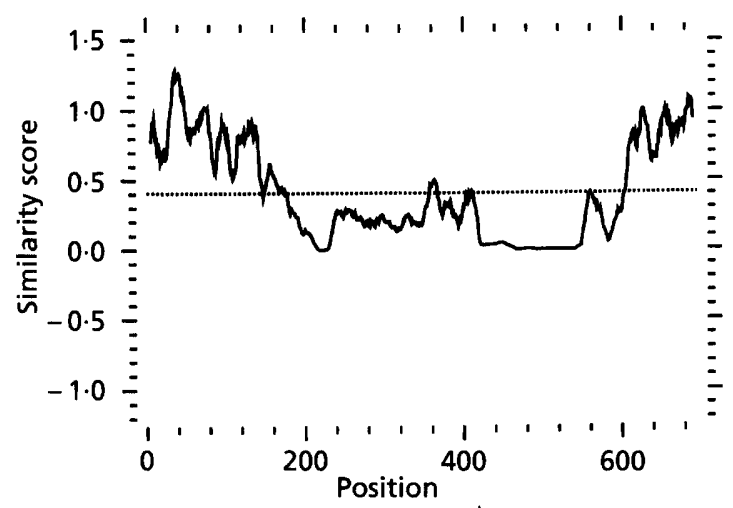

(b)

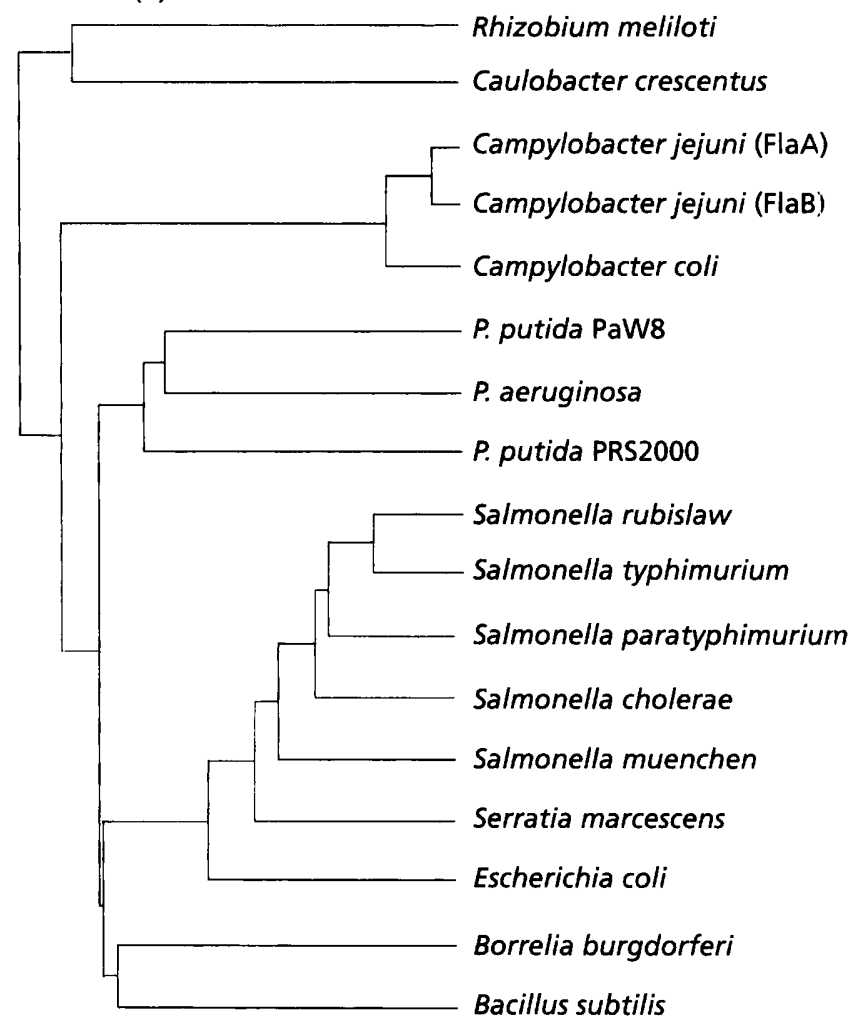

Fig. 7. A comparison of $P$. putida flagellins with other sequenced flagellin proteins. (a) Sequence similarity graph for all published flagellins including those of $P$. putida PaW8 and PRS2000. The length is derived from the longest flagellin, that of PaW8. (b) Dendrogram derived from the same flagellin protein sequences. Alignment of protein sequences was performed by the PILEUP Multiple Sequence Analysis program software package of the University of Wisconsin Genetics Computer Group. The clustering relationships created by PILEUP during muitiple sequence alignment are presented.

with other flagellins at the amino- and carboxy-terminal ends while exhibiting more divergence in central regions (Fig. 7). Unlike previously reported flagellins, which have been found to lack cysteine residues, the $P$. putida flagellins both contained three cysteine residues, although in common with other flagellins both lack histidine residues and have low numbers of tyrosine residues (one for PaW8; four for PRS2000).

Approximately $100 \mathrm{bp}$ upstream of the translational start of both $P$. putida flagellin genes lies a 27 base sequence varying in two positions (TNAAGCANCCCGCGCACCCGACGATAA) which occupies an identical position and is very similar to the putative $P$. aeruginosa flagellin promoter sequence (TAAAGCTCCCCAGGGAAGCGCCGATAA) (Totten \& Lory, 1990). These sequences are similar to the promoter sequence for several E. coli flagellin genes (Bartlett et al., 1988). The consensus sequence, TAAA- ${ }_{15}$-GCCGATAA, is recognized by a secondary sigma factor $\left(\sigma^{28}\right)$ in Bacillus subtilis and RpoF in E. coli (Arnosti \& Chamberlin, 1989). There are also sequences that conform to the GG-10-GC invariant consensus sequence for $\mathrm{RpoN}\left(\sigma^{54}\right)$-recognized promoters but none resemble the extended consensus sequence of CTGGYAYR-N ${ }_{4}$-TTGCA (Totten et al., 1990). As in P. aeruginosa, the flagellin gene initiating methionine codon in $P$. putida is preceded 8 bp by the sequence GAGG, a potential prokaryotic ribosome-binding site (Shine \& Dalgarno, 1974; Fig. 4). It has been demonstrated that although $P$. aeruginosa requires the $\mathrm{RpoN}$-encoded minor sigma factor $\left(\sigma^{54}\right)$ for transcription of flagellin (Totten $e t$ al., 1990), RpoF (encoding $\sigma^{28}$ ) is the likely functional consensus sequence for the promoter of the flagellin gene (Totten \& Lory, 1990). Two possible explanations were proposed by Totten \& Lory (1990): that RpoF is involved in the initiation of transcription of the flagellin and that RpoF exerts positive control of this transcription; or that RpoN may be required for transcription of the RpoF gene. In $P$. putida also the rpoN gene is required for production of flagella (Inouye et al., 1990). In both of the $P$. putida strains used in this study, $\mathrm{PaW} 8$ and PRS2000, RpoF-like recognition sequences occur in an identical position with respect to the transcriptional start site to the RpoF recognition sequence reported for $P$. aeruginosa flagellin. The consensus promoter sequence recognized by $\mathrm{RpoF}\left(\sigma^{28}\right)$-containing RNA polymerase, TAAA- $\mathrm{N}_{15}$ GCCGATAA, differs from the two $P$. putida RpoF-like recognition sequences by only two bases. This suggests that transcription of the flagellin gene may be regulated in $P$. putida in a similar manner to $P$. aeruginosa.

Our results from Southern hybridizations indicated that, as in $P$. aeruginosa (Totten \& Lory, 1990), the $P$. putida flagellin gene is found in a single copy in the chromosome. This suggests that in Pseudomonas, antigenic variation between strains is due to inter-strain divergence rather than to alterations in the expression of multiple genes as occurs in S. typhimurium (Smith et al., 1990), Campylobacter jejuni (Nuijten et al., 1991) and Rhizobium meliloti (Bergman et al., 1991). As anticipated, $P$. putida flagellin genes share considerable homology with other flagellins in their amino- and carboxy-terminal domains (Fig. 7a). In $S$. typhimurium such domains were found to be essential for export and polymerization of flagellin monomers (Homma et al., 1987a; Kuwajima et al., 1989). Central areas of the flagellins are less well conserved, containing hypervariable, non-essential regions (Fig. 7a). Indeed the toxin gene of Vibrio cholerae has been introduced into one 
such region of the flagellin gene of $S$. typhimurium; the resultant modified flagellin was assembled into flagella and the cells remained motile (Newton et al., 1989). $P$. putida PaW8 flagellin contains a substantial region (residues 425-545) of excess amino acid sequence not comparable to other sequenced flagellins [except for a 10 amino acid sequence (residues 472-481) matching with PRS2000 flagellin; Fig. 5]. Computer-assisted comparison of available flagellin protein sequences indicated that the two $P$. putida flagellins and the $P$. aeruginosa flagellin formed a closely-related distinct sub-grouping, although $\mathrm{PaW} 8$ flagellin appeared to be more closely related to $P$. aeruginosa flagellin than to PRS2000 flagellin (Fig. 7b). The presence of variable amounts of peptide sequence in the central areas of flagellins may make such studies difficult to interpret, with differences between strains swamping species differences in closely-related groups.

Determination of the precise location of the binding site for MLV1 was beyond the scope of this work. However, the most likely candidate areas for the location of the MLV1 epitope, indicated by computer analysis, are residues 273-280 (GALKLDGT), 289-300 (DDVLSTALGLA) and 513-517 (FKKG). Of the three most likely candidate sites for the MLV1 epitope, one lies within the area of excess amino acid sequence of PaW8 flagellin (residues 513-517) and the other two (residues 273-280 and 289-300) also lie within central areas of relatively poor sequence conservation. This is consistent with work on S. typhimurium (Smith \& Selander, 1990) and Borrelia burgdorferi (Rasiah et al., 1992) suggesting that the central variable areas of flagellins often account for antigenic diversity.

Preliminary experiments indicate that the sequence information obtained in this study can be used to design oligonucleotide primers for polymerase chain reaction (PCR) amplification of flagellin gene DNA from fluorescent pseudomonads. This has potential applications in the study of genetic diversity amongst mixed populations of pseudomonads or as a rapid assessment of strain type in cases, such as $P$. aeruginosa, where flagellin size can be used as an indicator (Allison et al., 1985; KellyWintenberg \& Montie, 1989). Genes such as those encoding flagellin offer an alternative to the study of populations using PCR amplification of $16 \mathrm{~S} r \mathrm{RNA}$ genes because of their potential for higher resolution at the subspecies level.

\section{Basal body genes and proteins}

Basal body structures consist of a number of rings (four: L, P, S and M, in S. typhimurium; five: L, P, E, S and M, in Caulobacter crescentus) mounted on a central rod (Khambaty \& Ely, 1992; Stallmeyer et al., 1989a, b). The S. typhimurium genes encoding L-, $\mathrm{P}$-, and M-ring proteins ( $f g H, f g I$, and $f i F$ ) have been sequenced (Jones et al., 1989), as has the $f g I$ region of $C$. crescentus (Khambaty \& Ely, 1992).

The order of the genes in $P$. putida ( $f g G-f g H-f g I$ ) corresponds to the same order within the $f g B$ operon of $S$. typhimurium, although analysis of the sequence directly downstream of $f g I$ in $P$. putida suggests that no equivalent gene to $f g J$ lies immediately downstream of $f g I$. The deduced molecular masses of the putative $P$. putida $\mathrm{FlgH}$ and FlgI proteins were $24.5 \mathrm{kDa}$ and $38.2 \mathrm{kDa}$ respectively, compared to $24.7 \mathrm{kDa}$ and $38.1 \mathrm{kDa}$ for $S$. typhimurium $\mathrm{FlgH}$ precursor and FlgI precursor respectively (Jones et al., 1989). In S. typhimurium, the $\mathrm{FlgH}$ and FlgI proteins undergo cleavage during export to the outer membrane (Homma et al., 1987b, c). The S. typhimurium $\mathrm{FlgH}$ and $\mathrm{FlgI}$ polypeptides contain a predicted transmembrane $\alpha$-helix in the region of their amino-terminal signal peptides (Jones et al., 1989). N-terminal signal peptides have a number of possible features (Oliver, 1985). There is often a basic amino terminus containing one to three positively charged amino acid residues. $P$. putida FlgH (residue 3) and FlgI (residue 5) both feature an arginine residue at the $\mathrm{N}$-terminus. This is generally followed by a hydrophobic core of 14-20 neutral, primarily hydrophobic amino acid residues. The protein sequences of $\mathrm{FlgH}$ and $\mathrm{FlgI}$ were analysed using the algorithms of Chou \& Fasman (1978), Garnier et al. (1978) and Kyte \& Doolittle (1982). The putative P. putida FlgH protein contained no predicted transmembrane $\alpha$-helix in its $\mathrm{N}$ terminal region although there is a possible hydrophobic core of approximately 20 amino acids. The putative $P$. putida FlgI protein contained a 22 amino acid $\mathrm{N}$-terminal hydrophobic region within which an $\alpha$-helix (in the area of residues 14-22) was predicted by both the ChouFasman (1978) and Garnier et al. (1978) analyses. The $P$. putida $\mathrm{FlgH}$ protein sequence, particularly at the $\mathrm{N}$ terminus, differed far more from the equivalent $S$. typhimurium protein than did the $P$. putida FlgI protein sequence $(48 \cdot 8 \%$ similarity compared with $66 \cdot 7 \%)$. Despite the differences observed, it is possible that $P$. putida $\mathrm{FlgH}$ and $\mathrm{FlgI}$ both contain N-terminal signal peptides. In $\mathrm{FlgH}$ there is a possible cleavage site adjacent to the sequence LAG (Cys-19). In FlgI there are three possible cleavage sites but alignment with the $S$. typhimurium FlgI sequence suggests a site adjacent to AQA (Glu-23) to be the most likely.

The overall amino acid similarity between the FlgI proteins of $P$. putida, $S$. typhimurium and $C$. crescentus (Khambaty \& Ely, 1992) is high. Although the sequence is incomplete, it is clear that the putative $f g G$ gene of $P$. putida PaW8 shares considerable homology with the $S$. typhimurium flgG gene. The $\mathrm{FlgH}$ protein appears to be less well conserved than FlgI or FlgG, suggesting that its structural role allows more scope for amino acid sequence variation. Flagellar genes are organized in transcriptional units located apart on the bacterial chromosome (Macnab, 1992). Such multicistronic operons often display complex patterns of gene regulation involving a number of transcription factors forming a regulatory hierarchy to control the relative stoichiometries of various gene products required for the production of macromolecular assemblies. It may not be surprising therefore that a mutation in a $P$. putida basal body structural gene ( $f g I$, encoding P-ring protein) could severely reduce the production of the flagellar filament protein, flagellin, 
which requires for its assembly an intact basal body structure. Alternatively, it could be that flagellin protein is synthesized, not assembled correctly and excreted from the cell. Temporal and spatial control of synthesis has been observed in the control of flagellar assembly in $C$. crescentus (Champer et al., 1987), E. coli (Komeda, 1986) and S. typhimurium (Kutsukake et al., 1990). Indeed two flgI mutants of $C$. crescentus have been shown to possess reduced intracellular levels of 25 and $27.5 \mathrm{kDa}$ flagellins (Khambaty \& Ely, 1992). In S. typhimurium the gap between the $f g G$ and $f g H$ genes is unusually large and contains an inverted repeat sequence thought to be involved in the formation of a stem-loop structure that may play a regulatory role (Jones et al., 1989). No such structure was observed in the smaller gap (36 bp compared to $64 \mathrm{bp}$ ) between the putative $f g G$ and $f g H$ in $P$. putida. The absence of such similarities coupled with the apparent lack of a $f g J$ gene immediately downstream of $f g H$ suggests that the organization and regulation of basal body structural genes in P. putida and S. typhimurium may differ.

\section{ACKNOWLEDGEMENTS}

We would like to thank Professor Stephen Lory for the provision of strains and M. Partis for assistance with computer analysis. This work was supported by Project Grant GR3/7466A from the Natural Environment Research Council.

\section{REFERENCES}

Aitken, A., Geisow, M. J., Findlay, J. B. C., Holmes, C. \& Yarwood, A. (1989). Peptide preparation and characterization. In Protein Sequencing, a Practical Approach, pp. 43-68. Edited by J. B. C. Findlay \& M. J. Geisow. Oxford: IRL Press.

Albertini, A. M., Caramori, T., Crabb, W. D., Scoffone, F. \& Galizzi, A. (1991). The fla $A$ locus of Bacillus subtilis is part of a large operon coding for flagellar structures, motility functions, and an ATPaselike polypeptide. J Bacteriol 173, 3573-3579.

Allison, J. S., Dawson, M., Drake, D. \& Montie, T. C. (1985). Electrophoretic separation and molecular weight characterization of Pseudomonas aeruginosa $\mathrm{H}$-antigen flagellins. Infect Immun 49, 770-774.

Arnosti, D. N. \& Chamberlin, M. J. (1989). Secondary $\sigma$ factor controls transcription of flagellar and chemotaxis genes in Eschericbia coli. Proc Natl Acad Sci US A 86, 830-834.

Bartlett, D. H., Frantz, B. B. \& Matsumura, P. (1988). Flagellar transcriptional activators $\mathrm{FlbB}$ and FlaI: gene sequences and $5^{\prime}$ consensus sequences of operons under FlbB and FlaI control. J Bacteriol 170, 1575-1581.

Bergman, K., Nulty, E. \& Su, L. H. (1991). Mutations in the two flagellin genes of Rbizobium meliloti. J Bacteriol 173, 3716-3723.

Bolivar, F. (1978). Construction and characterisation of new cloning vehicles. III. Derivatives of plasmid pBR322 carrying unique EcoRI sites for selection of EcoRI generated recombinant DNA molecules. Gene 4, 121-136.

Bolivar, F., Rodriguez, R. L., Green, P. J., Belach, H. C., Boyer, H. W., Crosa, J. J. \& Falkow, S. (1977). Construction and characterization of new cloning vehicles. II. A multi-purpose cloning system. Gene 2, 95-113.

Boulnois, G. J., Varley, J. M., Sharpe, G. S. \& Franklin, F. C. H. (1985). Transposon donor plasmids, based on ColIb-P9, for use in
Pseudomonas putida and a variety of other Gram-negative bacteria. Mol \& Gen Genet 200, 65-67.

Champer, R., Dingwall, A. \& Shapiro, L. (1987). Cascade regulation of Caulobacter flagellar and chemotaxis genes. J Mol Biol 194, 71-80.

Chou, P. Y. \& Fasman, G. D. (1978). Prediction of the secondary structure of proteins from their amino acid sequences. Adv Enzymol $47,45-148$.

Cohen, S. N., Chang, A. C. Y. \& Hsu, C. L. (1972). Nonchromosomal antibiotic resistance in bacteria: genetic transformation of Escherichia coli by $\mathrm{R}$ factor DNA. Proc Natl Acad Sci USA 69, 2110-2114.

Dower, W. J., Miller, J. F. \& Ragsdale, C. W. (1988). High efficiency transformation of E. coli by high voltage electroporation. Nucleic Acids Res 16, 6127-6145.

Garnier, J., Osguthorpe, D. J. \& Robson, B. (1978). Analysis of the accuracy and implications of simple methods for predicting the secondary structure of globular proteins. J Mol Biol 120, 97-120.

Gassmann, G. S., Jacobs, E., Deutzmann, R. \& Gobel, U. B. (1991). Analysis of the Borrelia burgdorferi GeHo fla gene and antigenic characterization of its product. $J$ Bacteriol 173, 1452-1459.

Gill, P. R. \& Agabian, N. (1983). The nucleotide sequence of the $M_{\mathrm{r}}$ $=28,500$ flagellin gene of Caulobacter crescentus. J Biol Chem 258, 7395-7401.

Girvitz, S. C., Bacchetti, S., Rainbow, A. J. \& Graham, F. W. (1980). A rapid and efficient procedure for the purification of DNA from agarose gels. Anal Biochem 106, 492-496.

Harlow, E. \& Lane, D. (1988). Antibodies: a Laboratory Manual, Cold Spring Harbor, NY: Cold Spring Harbor Laboratory.

Harshey, R. M., Estepa, G. \& Yanagi, H. (1989). Cloning and nucleotide sequence of a flagellin-coding gene (bag) from Serratia marcescens 274 . Gene 79, 1-8.

Holmes, D. S. \& Quigley, M. (1981). A rapid boiling method for the preparation of bacterial plasmids. Anal Biochem 114, 193-197.

Homma, M., Fujita, H., Yamaguchi, S. \& lino, T. (1987a). Regions of Salmonella typhimurium flagellin essential for its polymerization and excretion. J Bacteriol 169, 291-296.

Homma, M., Komeda, Y., lino, T. \& Macnab, R. M. (1987b). The flaFIX gene product of Salmonella typbimurium is a flagellar basal body component with a signal peptide for export. J Bacteriol 169, 1493-1498.

Homma, M., Ohnishi, K., lino, T. \& Macnab, R. M. (1987c). Identification of flagellar hook and basal body gene products (FlaV, FlaVI, FlaVII, and FlaVIII) in Salmonella typhimurium. J Bacteriol 169, 3617-3624.

Homma, M., Kutsukake, K., Hasebe, M., lino, T. \& Macnab, R. M. (1990). A family of structurally related proteins in the flagellar basal body of Salmonella typhimurium. J Mol Biol 211, 465-477.

Inouye, S., Kimoto, M., Nakazawa, A. \& Nakazawa, T. (1990). Presence of flagella in Pseudomonas putida is dependent on the $n \operatorname{tr} A$ (rpoN) gene. Mol \& Gen Genet 221, 295-298.

Jones, C. J., Homma, M. \& Macnab, R. M. (1989). L-, P-, and MRing proteins of the flagellar basal body of Salmonella typhimurium: gene sequences and deduced protein sequences. I Bacteriol 171, 3890-3900.

Joys, T. M. (1985). The covalent structure of phase-1 flagellar filament protein of Salmonella typhimurium and its comparison with other flagellins. J Biol Chem 260, 15758-15761.

Joys, T. M. \& Kim, H. (1978). Identification of $\varepsilon-N$-methyllysine residues in the phase-1 flagellar protein of Salmonella typhimurium. Microbios Lett 76, 5-68.

Kelly-Wintenberg, K., Anderson, T. \& Montie, T. C. (1990). 
Phosphorylated tyrosine in the flagellum filament protein of Pseudomonas aeruginosa. J Bacteriol 172, 5135-5139.

Kelly-Wintenberg, K. \& Montie, T. C. (1989). Cloning and expression of Pseudomonas aeruginosa flagellin in Escberichia coli. $J$ Bacteriol 171, 6357-6362.

Khambaty, F. M. \& Ely, B. (1992). Molecular genetics of the $f g I$ region and its role in flagellum biosynthesis in Caulobacter crescentus. J Bacteriol 174, 4101-4109.

Komeda, Y. (1986). Transcriptional control of flagellar genes in Escherichia coli K-12. J Bacteriol 168, 1315-1318.

Kutsukake, K., Ohya, Y. \& lino, T. (1990). Transcriptional analysis of the flagellar regulon on Salmonella typhimurium. J Bacteriol 172, $741-747$.

Kuwajima, G., Asaka, J. I., Fujiwara, T., Node, K. \& Kondo, E. (1986). Nucleotide-sequence of the hag gene encoding flagellin of Escherichia coli. J Bacteriol 168, 1479-1483.

Kuwajima, G., Kawagishi, I., Homma, M., Asaka, J. I., Kondo, E. \& Macnab, R. M. (1989). Export of an N-terminal fragment of Escherichia coli flagellin by a flagellum-specific pathway. Proc Natl Acad Sci US A 86, 4953-4957.

Kyte, J. \& Doolittle, R. F. (1982). A simple method for displaying the hydropathic character of a protein. J Mol Biol 157, 105-132.

Laemmli, U. K. (1970). Cleavage of structural proteins during the assembly of the head of bacteriophage T4. Nature 227, 680-685.

Logan, S. M., Trust, T. J. \& Guerry, P. (1989). Evidence for posttranslational modification and gene duplication of Campylobacter flagellin. J Bacteriol 171, 3031-3038.

Macnab, R. M. (1992). Genetics and biogenesis of bacterial flagella. Annu Rev Genet 26, 131-158.

McDonough, M. W. \& Smith, S. E. (1976). Molecular weight variation among bacterial flagellins. Microbios 16, 49-53.

Martin, J. H. \& Savage, D. C. (1988). Cloning, nucleotide sequence, and taxonomic implications of the flagellin gene of Roseburia cecicola. J Bacteriol 170, 2612-2617.

Morgan, J. A. W., Winstanley, C., Pickup, R. W. \& Saunders, J. R. (1991). Rapid immunocapture of Pseudomonas putida cells from lake water by using bacterial flagella. Appl Environ Microbiol 57, 503-509.

Newton, S. M. C., Jacob, C. O. \& Stocker, B. A. D. (1989). Immuneresponse to cholera-toxin epitope inserted in Salmonella flagellin. Scienct 244, 70-72.

Nuijten, P. J. M., Vanasten, F. J. A. M., Gaastra, W. \& Vanderzeijst, B. A. M. (1990). Structural and functional analysis of two Campylobacter jejuni flagellin genes. I Biol Chem 265, $17798-17804$.

Nuijten, P. J. M., Vanderzeijst, B. A. M. \& Newell, D. G. (1991). Localization of immunogenic regions on the flagellin proteins of Campylobacter jejuni 81116. Infect Immun 59, 1100-1105.

Oliver, D. (1985). Protein secretion in Escherichia coli. Annu Rev Microbiol 39, 615-648.

Pearson, W. R. \& Lipman, D. J. (1988). Improved tools for biological sequence comparison. Proc Natl Acad Sci USA 85, 2444-2448

Rasiah, C., Schiltz, E., Reichert, J. \& Voft, A. (1992). Purification and characterization of a tryptic peptide of Borrelia burgdorferi flagellin which reduces cross-reactivity in immunoblots and ELISA. $J$ Gen Microbiol 138, 147-154.
Sanger, F., Nicklen, S. \& Coulson, R. A. (1977). DNA sequencing with chain-terminating inhibitors. Proc Natl Acad Sci USA 74, 5463-5467.

Shine, J. \& Dalgarno, L. (1974). The $3^{\prime}$-terminal sequence of Escherichia coli $16 \mathrm{~S}$ ribosomal RNA: complementary to nonsense triplets and ribosome binding sites. Proc Natl Acad Sci USA 71, 1342-1346.

Simon, M. I., Emerson, S. U., Shaper, J. H., Bernard, P. D. \& Glazer, A. N. (1977). Classification of Bacillus subtilis flagellins. J Bacteriol 130, 200-204.

Smith, N. H. \& Selander, R. K. (1990). Sequence invariance of the antigen-coding central region of the phase 1 flagellar filament gene $(f i C)$ among strains of Salmonella typhimurium. J Bacteriol 172, 603-609.

Smith, N. H., Beltran, P. \& Selander, R. K. (1990). Recombination of Salmonella phase-1 flagellin genes generates new serovars. $J$ Bacteriol 172, 2209-2216.

Stallmeyer, M. J. B., Hahnenberger, K. M., Sosinsky, G. E., Shapiro, L. \& Derosier, D. J. (1989a). Image reconstruction of the flagellar basal body of Caulobacter crescentus. J Mol Biol 205, 511-518.

Stallmeyer, M. J. B., Aizawa, S.-I., Macnab, R. M. \& Derosier, D. J. (1989b). Image reconstruction of the flagellar basal body of Salmonella typhimurium. J Mol Biol 205, 519-528.

Totten, P. A. \& Lory, S. (1990). Characterization of the type a flagellin gene from Pseudomonas aeruginosa PAK. I Bacteriol 172, 7188-7199.

Totten, P. A., Lara, J. C. \& Lory, S. (1990). The rpoN gene product of $P$ seudomonas aeruginosa is required for expression of diverse genes, including the flagellin gene. $J$ Bacteriol 172, 389-396.

Towbin, H., Staehelin, J. \& Gordon, J. (1979). Electrophoretic transfer of proteins from polyacrylamide gels to nitrocellulose sheets: procedure and some applications. Proc Natl Acad Sci US A 76, 4350-4352.

Wei, L. N. \& Joys, T. M. (1986). The nucleotide sequence of the $H$ $l^{\mathrm{r}}$ gene of Salmonella rubislaw. Nucleic Acids Res 14, 8227.

Wieland, F., Paul, G. \& Sumper, M. (1985). Halobacterial flagellins are sulfated glycoproteins. J Biol Chem 260, 15180-15185.

Winstanley, C., Morgan, J. A. W., Pickup, R. W., Jones, J. G. \& Saunders, J. R. (1989). Differential regulation of lambda $p_{\mathrm{L}}$ and lambda $p_{\mathbf{R}}$ promoters by a $c \mathrm{I}$ repressor in a broad-host-range thermoregulated plasmid marker system. Appl Environ Microbiol 55, $771-777$.

Winstanley, C., Carter, J.P., Seasman, M., Morgan, J. A. W., Pickup, R. W. \& Saunders, J. R. (1993). A comparison of the survival of stable and unstable chromosomally-located $x y l E$ marker cassettes as an indicator of cell division within populations of Pseudomonas putida released into lake water and soil. Microb Releases 2, 97-107.

Worsey, M. J. \& Williams, P. A. (1975). Metabolism of toluene and xylenes by Pseudomonas putida (arvilla) $\mathrm{mt}-2$ : evidence for a new function of the TOL plasmid. J Bacteriol 124, 7-13.

Yanisch-Perron, C., Vieira, J. \& Messing, J. (1985). Improved M13 cloning vectors and host strains: nucleotide sequences of the M13mp18 and pUC19 vectors. Gene 33, 103-119.

Received 7 October 1993; revised 22 December 1993; accepted 1 March 1994. 